\title{
MATERNAL DEPRESSION AND NONVERBAL ATTUNEMENT
}

\author{
Kristīne Vende-Kotova \\ Riga Stradiņš University, Latvia
}

\begin{abstract}
Nonverbal attunement is when mother attunes with emotional state of the child by changing her nonverbal behaviour (posture, facial expressions, movement rhythm, speed, etc.) instead of using verbal means of expression such as naming child's activity, verbal reflection or interpretation. Mother's difficulty to attune with a child is associated with high rates of the psychopathology in children (Allen, Fonagy \& Baterman, 2008). The research aimed to determine whether and what are the correlations between mother's depression symptoms and to her ability nonverbally attune to her child. 30 mothers and their children participated in this part of the research by performed creative tasks. Maternal nonverbal attunement with a child was determined using the Nonverbal Attunement Scale (Vende \& Čukurs, 2011). Mothers also filled in the Beck Depression Inventory (BDI II Beck Depression Inventory; Beck, Steer \& Brown, 1996).

Research findings indicate that maternal depression symptoms are not correlated to maternal nonverbal attunement with a child, and that is inconsistent with existing research. There was additionally examined child's ability to attune nonverbally to the mother in relation with maternal depression symptoms. These results show that maternal depression symptoms are negatively correlated to child's ability to mirror the mother nonverbally.
\end{abstract}

Keywords: nonverbal attunement, mother depression symptoms.

\section{Introduction}

Nonverbal attunement, which has been researched in this thesis, is a similar notion to affect attunement, which is defined as the maternal ability to emotionally attune with her child's emotional state and to mirror it back to the child, thus causing him to feel that he and his needs are understood. Affect attunement is a key factor in ensuring the child's psycho-emotional and cognitive development, (Stern, 1985), and it includes both verbal and nonverbal aspects. Research shows that the mother's ability to attune with the child is significantly correlated to the development of secure attachment in a child (Atkinson et al, 2000; Bigelow et al., 2010; Laranjoa, Berniera \& Meins, 2008; Legerstee, Markova \& Fisher, 2007; Legerstee \& Varghese, 2001; Meins, Fernyhough, Fradley \& Tuckey, 2001; Slade, 2005; Ward \& Carlson, 1995), self-regulation skills (Eiden, Colder, Edwards \& Leonard, 2009), and mutual communication between the mother and the child (Grienenbeger, Kelly \& Slade, 2005). This attunement can be affected by factors such as mothers' own 
attachment style and alcoholism (Eiden, Colder, Edwards \& Leonard, 2009), mother's prejudices about the child's upbringing, her self-efficacy and child's temperament (Kiang, Moreno \& Robinson, 2004), maternal depression (Vliegen, Luyten \& Biringen, 2009), and activity of mirror neurons (Iacoboni \& Dapretto, 2006).

Nonverbal attunement is different from affect attunement in terms of special attention that is paid to ways the mother attunes with emotional state of the child by changing her nonverbal behaviour (posture, facial expressions, movement rhythm, speed, etc.). Kestenberg has expressed the view that, in order to understand how the child feels, the parent of the child has to align to the child's movement patterns and has to interact with them empathetically (Kestenberg, Lomani, Lewis \& Sossin, 1999). Kestenberg has also expressed the view that, in a relationship, there can be too much of alignment and certain amount of clashing in movements is necessary. This clashing is necessary at certain phases of child development, in order to promote the child's development (Lumsden, 2006; Loman \& Sossin, 2009). Nowadays, based on the ideas of Kestenberg and other practitioners, Meekums argues that promotion of nonverbal communication may contribute to an emotionally close relationship between parents and children, as well as facilitate child's secure attachment (Meekums, 1992).

Looking at the nonverbal attunement at early age, Tortora (Tortora, 2010) points that communication between mother and infant primarily takes place through facial expressions, posture, tone of voice, gestures and other activities which are complementary. This interaction creates shared framework of meaning between mother and child, helping the infant to organize an understanding about what is happening and what is to be expected. The understanding of the sequence of events helps the infant to form perception of oneself and the others, and, as a result, there develops an emotional relationship between mother and child. Looking at the nonverbal attunement, attention must be paid to such notion of psychology as joint attention. It is described as an individual's ability to attune shared attentiveness with other parties, and to realize that both parties are attuning jointly. Joint attention is essential for the overall development of the child, because it is an important basis for the formation of the communication process between mother and child (van Hecke et al., 2007).

Maternal depression, which is described as an individual's low mood and loss of interest, may negatively affect mother's ability to attune to the child. Maternal depression can be one of the aspects that influence the formation of disorganized attachment in child (Bakermans-Kranenburg, van Ijzendoorn \& Juffer, 2005). Children whose mothers are depressed tend to express more aggression interacting with friends. At pre-school age, these children are more 
often excluded from peers. In later years, interpersonal conflicts are formed more often (Mendes, Loureiro, Crippa, Gaya, García-Esteve \& Martín-Santos, 2012). Depressed mothers, being, on one hand, inaccessible, but on the other hand, irritable and, occasionally, overly involved in the child's life, cause stress in children, which may contribute to development of increased anxiety / depression and aggression (Gelfand \& Teti, 1990; Jaser et al., 2005; Palez, Field, Pickens \& Hart, 2008). Maternal depression is associated with less developed child's communication skills, increase of the likelihood that the child will also have a depression, increased levels of anxiety and the likelihood of internalizing and externalizing behavioral problems (Campbell, Matestic, von Stauffenberg, Mohan \& Kirchner, 2007, Institute of Medicine and National Research Council, 2009).

Novelty is that no research had been conducted on maternal nonverbal ability to attune with a child in relation to level of maternal depression features. Previous research has been conducted on mothers who have children in infancy, rather than primary school age, looking at general maternal sensitization but not at her ability to attune with a child nonverbally (Campbell, Matestic, von Stauffenberg, Mohan \& Kirchner, 2007; Donavan, Taylor \& Leavitt, 2007). The aim of the research is to determine whether and what are the correlations between maternal nonverbal attunement with a child and maternal depression symptoms.

\section{Method}

\section{Participants}

To achieve this objective 30 mothers took part at the research. Mothers performed creative tasks together with their children $(50 \%$ boys and $50 \%$ girls in age from 7 till 11 years, average child age 8,56 gadi, $\mathrm{SD}=1,16$ ). They agreed to take part in video filming, which included performing of the creative tasks, identifying skills of nonverbal attunement and ability to mirror nonverbally. Of all participants in the second phase, $65,6 \%$ had higher education, $12,5 \%$ had 1 st level professional higher education / vocational training, 18,8 \% had unfinished higher education, $3,1 \%$ had secondary education. In its turn, from all fathers of participants, 53,1\% had 1st level professional higher education / vocational training, 31,1\% had higher education, 6,3\% had basic education, 6,3\% had secondary education, $3,1 \%$ (1 father) had unfinished higher education.

\section{Instruments}

Beck Depression Inventory (BDA II) (BDI - II Beck Depression Inventory, Beck, Steer \& Brown, 1996). There are 21 statements altogether by which person's emotional and physical states during the past two weeks are measured. Each statement has a set of at four possible answer choices (0-3), from which 
the respondent must choose the one that best describes the way he has been feeling in last two weeks. By adding up all answers, the total score can be calculated for assessing the depression's severity. Is considered that summary rate 5-9 is related to the normal mood changes, 10-18 indicates features of depression, 19-29 indicates moderate depression, and 30-63 indicates severe depression. The sum over 40 is too big for even the very depressed person, but the sum below 4 may be a sign of depression denial. Cronbach alpha coefficient of the research sample is 0,87 . The Inventory in Latvia has been adapted by S. Voitkane and S. Miezite (Voitkane \& Miezite, 2001).

Nonverbal Attunement Scale (NAS) also was created for this research. Originally it was planned to use Kestenberg's motion profile because it is an instrument that looks at the movement and its qualities in great detail, and taking certain steps, it is possible to draw up a schematic motion profile for the individual. Also, historically, this profile has been used to analyze mother's and child's nonverbal interaction. However, in a first pilot study, it was concluded that this instrument does not allow to assess maternal nonverbal attunement in a given moment, it only allows to compare whether mothers within a specified time period use movement qualities as much or as little as their children. For these reasons, based on views of Kestenberg, Stern and other authors mentioned in this dissertation, there was created the Nonverbal Attunement Scale (Vende \& Čukurs, 2011).

Thus, the mother's ability to attune nonverbally was evaluated in the first task, „Egg salvage”, on 5-point scale, where „Egg salvage” video recording was evaluated in relation to the dimensions ,joint attention” and „bodily coherence”. „Egg salvage" video recording was evaluated by rating each minute from 1-5 and then calculating averages of these ratings corresponding to each subscale ,joint attention” and „bodily coherence”. In turn, in the task „The mirror” the mother and the child had to reflect each other movements on 3-point scale according to certain criteria. Standardized $t$ values were calculated from the data obtained during each task. The combined rate of the mother's skill to attune with the child nonverbally was obtained by adding up points from three subscales: ,joint attention", "bodily coherence" and „mother's ability to mirror the child nonverbally".

In order to determine the credibility of the assessment, two experts rated 7 pairs of data and coherence of ratings was calculated using the Pearson correlation coefficient between the ratings given by both evaluators. Obtained correlation coefficient was $r=0,96 ; p<0,01$, which confirms high reliability, therefore obtained observation data are usable in the research.

\section{Procedure}

Mothers who in the Demographic Profile Questionnaire had given their contact information, were contacted, and agreement was reached on a mutually 
beneficial time of meeting. Meetings took place at the premises of Faculty of Education, Psychology and Art, University of Latvia, or at the premises of author's place of work. At a meeting with participants of the research, mother's and child's consent to be filmed was confirmed. Participants of the research were informed about the principles of confidentiality and the fact that no one outside the research team without the consent of the participants will be able to see the videos. As the meeting went on, participants were introduced to the first creative task.

Creative task „Egg salvage”.

Materials: boiled egg, wide and narrow adhesive tape, 6 crochet thread spools, 2 scissors, 6-8 plastic cups, paper clips, rubber, A4 or larger sheets of paper, $90 \mathrm{~cm}$ cotton wool pieces, stapler, staples, 4 garden stick, box of $90 \mathrm{~cm}$ long cocktail straws, cardboard box, box of snack sticks, video camera and tripod for filming the task. The egg was tied to the ceiling at a height of an adult's face.

Instruction: Using the given materials, create a system that will prevent the egg break when the thread, with which the egg is attached to the ceiling, will be cut. During the task nothing is allowed to do with the egg or the thread. Everything else is allowed. Time: 15 minutes. You will be informed when the last 5 and 3 minutes before the end of task time remain.

Creative task ,"The mirror".

Materials: video camera, tripod, 2 scarves (optional).

Instruction:_the next task will give you the chance to move, and its name is „, the mirror". During the task, one of you will be the A, and you will be able to choose slow or fast music and to move while it plays. As an A, you can exercise, dance, stretch or do whatever you do every morning in front of the mirror. You may do whatever you wish to do at the moment, remembering that there is no „right" or ,wrong” in this task. In turn, the B will play a mirror and will try to reflect what the A is doing.

The A needs to move in such a way that the B can repeat the motion, and so that it respects the dignity. You are not allowed to talk during the task. Please choose who will be the A and who will be the B the first.

The data of the research were collected from late May, 2012, to middle of November, 2013. Participants took part in the research on an optional basis.

\section{Results}

Results in 1st table shows that maternal depression symptoms are negatively correlated to child's ability to mirror the mother nonverbally ( $r=-$ $0,45, p<0,5)$. These results show: the more mothers indicate depression symptoms, the less children mirror their mother. 
Maternal depression symptoms are not correlated to maternal nonverbal attunement with a child, and that is inconsistent with existing research.

\section{1.tab. Correlation coefficients between maternal depression symptoms and total rates of maternal nonverbal attunement, and rates in dimensions 'joint attention', 'bodily coherence' and 'maternal nonverbal mirroring' $(n=30)$}

\begin{tabular}{lccccccc}
\hline & M & SD & $\begin{array}{c}\text { Maternal } \\
\text { nonverbal } \\
\text { attunement } \\
\text { index }\end{array}$ & $\begin{array}{c}\text { Joint } \\
\text { attention }\end{array}$ & $\begin{array}{c}\text { Bodily } \\
\text { coherence }\end{array}$ & $\begin{array}{c}\text { Maternal } \\
\text { nonverbal } \\
\text { mirroring }\end{array}$ & $\begin{array}{c}\text { Child's } \\
\text { ability to } \\
\text { mirror the } \\
\text { mother }\end{array}$ \\
\hline $\begin{array}{l}\text { Maternal } \\
\text { depression }\end{array}$ & $\begin{array}{c}8,8 \\
7\end{array}$ & 6,74 & 0,03 & 0,12 & 0,08 & $-0,23$ & $-0,45^{*}$ \\
\hline
\end{tabular}

$* \mathrm{p}<0,05$

\section{Discussion}

Maternal depression symptoms are not correlated to maternal nonverbal attunement. Admittedly, other studies have shown that maternal depression affects her ability to create an emotional bond with the child and, if the mother is depressed, it can have a negative impact on her ability to create a bond (Vliegen, Luyten \& Biringern, 2009; Tarabulsy et al., 2005; Jacobvitz, Leon \& Hazen, 2006). However, it is important to note that the majority of previous research has been conducted with mothers who interacted with infants or children of preschool age. Perhaps the results of this study could be explained by the fact that mutual correlation between maternal attunement and maternal depression symptoms is more expressed at the child's early age and may apply less in middle school age, and also, in previous research, nonverbal aspect of attunement was not examined in particular. Child's ability to mirror the mother nonverbally is negatively correlated to maternal depression symptoms. That is, the more mother indicate depression symptoms, the less the child mirrors a mother. So far, there are no studies on how child mirrors mother nonverbally in relation to mother's depression, and there is no theoretical overview of the subject. However, given the previous results and observations from the qualitative part of the research ${ }^{1}$, in my opinion, mother's depression symptoms make it difficult for her to build an emotional bond with the child. Consequently, the child does not interact with the mother at a level required to be able to mirror the mother. In my opinion, these results in a way are explained

\footnotetext{
${ }^{1}$ This article and the results presented here are part of the docotral theses "Maternal Nonverbal Attunement, Depression Symptoms, Emotion Regulation Strategies And Child's Behaviour Problems" (Vende, 2014)
} 
by the other findings of the research ${ }^{2}$. That is to say, a child's ability to mirror the mother nonverbally statistically significantly correlated with subscales rulebreaking behaviour, and this means that, the more the child is characterized by a rule-breaking behaviour, the less he tends to mirror his mother. As noted in the literature, depressed mothers, on the one hand, are inaccessible, on the other hand, they often are too anxious and irritable. Thus, their children are experiencing stress, which can raise the anxiety and to encourage the development of aggression (Gelfand \& Teti, 1990; Palez, Field, Pickens \& Hart, 2008). Probably, just described behaviour of mother and the child's reaction to it determines that a child may not only feel anxiety and aggression, but also want to distance himself from the mother. Another explanation for this research finding could be the so called ,child effect”. Namely, the behaviour of the child and his ability to build a social relationship is also influenced by genetic factors, such as the child's temperament (Phillips et al., 2012), that was not addressed in this study, but could have affected the results of the research. In any case, this topic would need to be explored in future research. In my opinion, these results in a way are explained by the other findings of this research. Namely, there is a tendency to negative correlation between child's ability to mirror mother nonverbally and subscale rule-breaking behaviour, which shows: the more child tends to violate the rules, the less he is able or willing to mirror actions of his mother.

\section{Practical application of the research}

Practical application of this research is that the presentation of the findings of research to the general public can contribute to the understanding of correlation between the emotional state of the mother (in the context of this study, her depression) and child's behavior, as well as the impact of emotion regulation strategies on human well-being. Also the practical application of this study I see in regards to the development of Nonverbal Attunement Scale, which allows assessing mother's ability to attune nonverbally to a child, based on developed criteria, rather than subjective and general observations; this tool is available for the professionals to use in their research or practical work. For practicing psychologists, this tool would allow assessing the interaction between mother and child, and, based on observation, to provide specific and clear recommendations. In turn, adapting this method in the research, it could also be used to observe children of different age and to observe not only their interactions with mothers but also with other adults and peers.

\footnotetext{
${ }^{2}$ This article and the results presented here are part of the docotral theses "Maternal Nonverbal Attunement, Depression Symptoms, Emotion Regulation Strategies And Child's Behaviour Problems” (Vende, 2014)
} 
The main limitations of this research: the relatively small number of subjects in the second phase of the research, as well as the fact that mothers, who took part in second phase, came from relatively privileged backgrounds, they were working, and only some of their children had expressed externalizing behavioral problems. It would be desirable to have a larger number of participants. It would be desirable to have Child Behaviour Checklist filled in also by a child's teacher. Directions of further researches: longitudinal research, which would allow exploring correlations between variables over the time. During the follow-up research it might be required to review the chosen methods and to reassess, which questionnaires would be best for future research. In my opinion, further research should be developed in this direction: to assess children's emotion regulation skills with the aim of understanding children's emotion regulation skills in correlation to maternal emotion regulation strategies, maternal depression and rates of child's externalizing and internalizing behaviour. So far, there is no research on whether and how the child's emotion regulation skills are related to the mother's ability to attune nonverbally and to mirror the child. Also, it would be important to explore whether and how the child's emotion regulation skills are related to the child's overall ability to mirror the other human being.

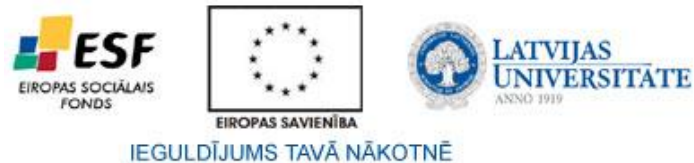

This work has been supported by the European Social Fund within the project Support for Doctoral Studies at University of Latvia ”Nr.2009/0138/1DP/1.1.2.1.2./ 09/IPIA/VIAA/004.

\section{References}

Allen, J. G., Fonagy, P., \& Baterman, A. W. (2008). Mentalizing in clinical practice. Washington: American Psychiaric Publishing Inc.

Atkinson, L., Niccols, A., Paglia, A., Coolbear, J., \& Parker, K. C. H. (2000). A MetaAnalysis of time between maternal sensitivity and attachment assessments: Implications for internal working models in infancy/toddlerhood. Journal of Social \& Personal Relationships, 17 (6), 791-811.

Bakermans-Kranenburg, M., van Ijzendoorn, M., \& Juffer, F. (2005). Disorganized infant attachment and preventative interventions: A review and meta-analysis. Infant Mental Health Journal, 26 (3), 191-216.

Beck, A. T., Steer, R. A., \& Brown, G. K. (1996). BDI-II Beck Depression Inventory - 2nd edition Manual. San Antonio, TX: The Psychological Corporation.

Bigelow, A. E., \& MacLean, P. K. (2010). Maternal sensitivity throughout infancy: continuity and relation to attachment security. Infant Behaviour \& Development, 33, 50-60.

Campbell, S. B., Matestic, P., von Stauffenberg, C., Mohan, R., \& Kirchner, T. (2007). Trajectories of maternal depressive symptoms, maternal sensitivity, and children's 
functioning at school entry. Developmental Psychology, 43 (5), 1202-1215.

Donovan, W., Taylor, N., \& Leavitt, L. (2007). Maternal self-efficacy, knowledge of infant development, sensory sensitivity, and maternal response during interaction. Developmental Psychology, 43 (4), 865-876.

Eiden, R., Colder, C., Edwards, E., \& Leonard, K. (2009). A Longitudinal study of social competence among children of alcoholic and nonalcoholic parents: Role of parental psychopathology, parental warmth, and self-regulation. Psychology of Addictive Behaviors, 23 (1), 36-46.

Gelfand, D. M., \& Teti, D. M. (1990). The effects of maternal depression on children. Clinical Psychology Review, 106, 329-353.

Grienenbeger, J., Kelly, K., \& Slade, A. (2005). Maternal reflective functioning, motherinfant affective communication, and infant attachment: Exploring the link between mental states and observed caregiving behavior in the intergenerational transmission of attachment. Attachment \& Human Development, 7 (3), 299-311.

Iacoboni, M., \& Dapretto, M. (2006). The mirror neuron system and the consequences of its dysfunction. Nature Reviews Neuroscience, 7, 942-951.

Institute of Medicine and National Research Council. (2009). Depression in parents, parenting, and children: Opportunities to improve identification, treatment, and prevention. Washington, DC: The National Academies Press.

Jacobvitz, D., Leon, K., \& Hazen, N. (2006). Does expectant mothers' unresolved trauma predict frightening maternal behavior? Risk and protective factors. Development and Psychopathology, 18, 363-379.

Jaser, S. S., Fear, J. M., Reeslund, K. L., Champion, J. E., Reisling, M. M., \& Compas, B. E. (2008). Maternal sadness and adolescents' responses to stress in offspring of mothers with and without history of depression. Journal of clinical child and adolescent psychology, 37, 736-746.

Kestenberg, J., Loman, S., Lewis, P., \& Sossin, M. (1999). The meaning of movement: Developmental and clinical perspectives of the Kestenberg Movement Profile. London: Gordon and Breach Publishers.

Kiang, L., Moreno, A. J., \& Robinson, J. L. (2004). Maternal preconceptions about parenting predict child temperament, maternal sensitivity, and children's empathy. Developmental Psychology, 40 (6), 1081-1092.

Laranjoa, J., Berniera, A., \& Meins, E. (2008). Associations between maternal mindmindedness and infant attachment security: Investigating the mediating role of maternal sensitivity. Infant Behavior \& Development, 31, 688-695.

Legerstee, M., Markova, G., \& Fisher, T. (2007). The role of maternal affect attunement in dyadic and triadic communication. Infant Behavior \& Development, 30, 296-306.

Legerstee, M., \& Varghese, J. (2001). The role of maternal affect mirroring on social expectancies in three-month- old infants. Child Development, 72 (5), 1301-1313.

Loman, S., \& Sossin, K. M. (2009). Applying the Kestenberg Movement Profile in dance/movement therapy. In: Chaiklin, S., \& Wengrower, H. (Eds.). The Art and Science of Dance/Movement Therapy. Life is Dance. New York: Routledge, 237-265.

Lumsden, M. (2006). The affective self and affect regulation in dance movement therapy. In: Koch, S., \& Brauninger, I. (Eds.). Advances in dance/movement therapy. Logos: Berlin, $29-40$.

Meekums, B. (1992). Dance movement therapy: A creattive psychotherapeutic approach. London: SAGE. 
Meins, E., Fernyhough, C., Fradley, E., \& Tuckey, M. (2001). Rethinking maternal sensitivity: Mothers' comments on infants' mental processes predict security of attachment at 12 months. Journal of Child Psychology and Psychiatry, 42, 637-648.

Mendes, A. V., Loureiro, S. R., Alexandre Crippa, J. A., Gaya, C., García-Esteve, L., \& Martín-Santos, R. (2012). Mothers with depression, school-age children with depression? A Systematic review. Perspectives in Psychiatric Care, (48), 138-148.

Paleaz, M., Field, T., Pickens, J. N., \& Hart, S. (2008). Disengaged and authoritarian parenting behavior of depressed mothers with their toddlers. Infant Behaviour and Development, 31, 145-148.

Phillips, D., Crowell, N. A., Sussman, A. L., Gunnar, M., Fox, N., Hane, A. A., \& Bisgaier, J. (2012). Reactive Temperament and Sensitivity to Context in Childcare. Social Development, 21 (3), 628-643.

Slade, A. (2005). Parental reflective functioning: An introduction. Attachment \& Human Development, 7 (3), 269-281.

Slade, A., Grienenberger, J., Bernbach, E., Levy, D., \& Locker, A. (2005). Maternal reflective functioning, attachment, and the transmission gap: A preliminary study. Attachment \& Human Development, 7 (3), 283-298.

Stern, D. N. (1985). The interpersonal world of the infant. A view from psychoanalysis and developmental psychology. New York: Basic Books, Inc.

Tarabulsy, G., Provost, M., Moss, E., Bernier, A., Maranda, J., Larose, S., Larose, J., \& Tessier, R. (2005). Another look inside the gap: Ecological contributions to the transmission of attachment in a sample of adolescent mother-infant dyads. Developmental Psychology, 41 (1), 212-224.

Tortora, S. (2010). The essential role of the body: How movement and nonverbal experience inform implicit knowing and intersubjectivity in early childhood development. In: Bender, S. (Ed.) Bewegungsanalyse von Interaktionen. Movement analysis of interaction. Logos: Berlin, 125-139.

Van Hecke, A., Mundy, P. C., Acra, C. F., Block, J. J., Delgado, C. E. F., Parlade, M. V., Neal, A. R., Meyer, J. A., \& Pomares, Y. B. (2007). Infant Joint Attention, Temperament, and Social Competence in Preschool Children. Child Development, 78 (1), 53-69.

Vende, K. (2014). Maternal Nonverbal Attunement, Depression Symptoms, Emotion Regulation Strategies And Child's Behaviour Problems.Unpublished doctoral theses.

Vende, K., \& Čukurs, E. (2011). A pilot study: Level of nonverbal attunement between mother and children with secure and insecure attachment style. 11th European Conference on Psychological Assessment. Book of programme-abstracts.

Voitkane, S., \& Miezite, S., (2001). Pirma kursa studentu adaptacijas problemas. Baltijas Psihologijas žurnals, 2 (1), 43-58.

Vliegen, N., Luyten, P., \& Biringen, Z. (2009). A multimethod perspective on emotional availability in the postpartum period, Parenting, 9 (3\&4), 228-243.

Ward, M. J., \& Carlson, E. A. (1995). Associations among adult attachment representations, maternal sensitivity, and infant-mother attachment in a sample of adolescent mothers. Child Development, 66, 69-79 